\title{
EVALUATION OF A URANIUM ZIRCONIUM HYDRIDE FUEL ROD OPTION FOR CONVERSION OF THE MIT RESEARCH REACTOR (MITR) FROM HIGHLY-ENRICHED URANIUM TO LOW-ENRICHED URANIUM
}

\author{
F. E. DUNN ${ }^{1}$, E. H. WILSON, AND E. E. FELDMAN \\ Argonne National Laboratory, 9700 S. Cass Avenue, Argonne, Illinois 60439 \\ K. SUN, C. WANG, L-W HU \\ MIT Nuclear Reactor Laboratory \\ 138 Albany Street, Cambridge, Massachusetts 02139
}

\begin{abstract}
The conversion of the Massachusetts Institute of Technology Reactor (MITR) from the use of highly-enriched uranium (HEU) fuel-plate assemblies to low-enriched uranium (LEU) by replacing the HEU fuel plates with specially designed General Atomics (GA) uranium zirconium hydride (UZrH) LEU fuel rods is evaluated. The margin to critical heat flux (CHF) in the core, which is cooled by light water at low pressure, is evaluated analytically for steady-state operation. A form of the Groeneveld CHF lookup table method is used and described in detail. A CHF ratio of 1.41 was found in the present analysis at $10 \mathrm{MW}$ with engineering hot channel factors included. Thus, the nominal reactor core power, and neutron flux performance, would need to be reduced by at least $25 \%$ in order to meet the regulatory requirement of a minimum CHF ratio of 2.0 .
\end{abstract}

KEYWORDS: MITR, TRIGA, Low-enriched Uranium, Reactor Conversion

\begin{abstract}
The conversion of the Massachusetts Institute of Technology Reactor (MITR) from the use of highly-enriched uranium (HEU) fuel-plate assemblies to low-enriched uranium (LEU) by replacing the HEU fuel plates with specially designed General Atomics (GA) uranium zirconium hydride (UZrH) LEU fuel rods is evaluated. The margin to critical heat flux (CHF) in the core, which is cooled by light water at low pressure, is evaluated analytically for steady-state operation. A form of the Groeneveld CHF lookup table method is used and described in detail. A CHF ratio of 1.41 was found in the present analysis at $10 \mathrm{MW}$ with engineering hot channel factors included. Thus, the nominal reactor core power, and neutron flux performance, would need to be reduced by at least $25 \%$ in order to meet the regulatory requirement of a minimum $\mathrm{CHF}$ ratio of 2.0.
\end{abstract}

KEYWORDS: MITR, TRIGA, Low-enriched Uranium, Reactor Conversion

\footnotetext{
${ }^{1}$ Corresponding author at: Argonne National Laboratory, 9700 S. Cass Ave., Argonne, IL 60439.

E-mail address: fedunn@anl.gov
} 


\section{INTRODUCTION}

\subsection{Current HEU Fuel Plate Core}

The Massachusetts Institute of Technology Reactor (MITR) core has a hexagonal design that contains twenty-seven fuel positions in three radial rings $(A, B$, and $C)$, as shown in Figure 1 , and is licensed by U.S. Nuclear Regulatory Commission to operate at $6 \mathrm{MW}$. Typically at least three of these positions (two in the A-ring and one in the B-ring) are filled with either an in-core experimental facility or a solid aluminum dummy element to reduce power peaking. The remaining positions are filled with standard MITR fuel elements. Each rhomboid-shaped fuel element currently contains 15 aluminum-clad fuel plates using highly-enriched uranium (HEU), 93\% enriched, in an aluminide cermet matrix with a fuel thickness of $0.76 \mathrm{~mm}$ and a length of $56.83 \mathrm{~cm}$. The cladding of each fuel plate is machined with $0.25 \mathrm{~mm}$ longitudinal fins to increase heat transfer to the coolant. The fuel has an overall density of 3.7 $\mathrm{g} / \mathrm{cm}^{3}$, with a total loading of $506 \mathrm{~g}$ of ${ }^{235} \mathrm{U}$ in each element. ${ }^{1}$

The core is light water moderated and cooled and is surrounded by a heavy water reflector. Boron-impregnated stainless steel control blades are located at the periphery of the core on each side of the hexagon, and have a total travel length of $53.34 \mathrm{~cm}$. In addition, as shown in Figure 1, fixed absorbers can be installed in the upper axial region of the core in a hexagonal configuration between the $A$ and $B$ rings as well as in three radial arms extending to the edge of the core.

\subsection{Proposed LEU U10Mo Fuel-Plate Core}

Conversion of high performance research and test reactors, including MITR, from HEU to lowenriched uranium (LEU) will require fuel with a high uranium density, at least $14 \mathrm{gU} / \mathrm{cm}^{3}$, to maintain adequate performance with a ${ }^{235} \mathrm{U}$ enrichment of less than $20 \%{ }^{2}$ The five domestic high performance research and test reactors all use plate-type fuel. High density plate type fuel is currently under development by the Reduced Enrichment for Research and Test Reactors (RERTR) program. For the U.S. High Performance Research Reactor conversion program, the fuel is a monolithic alloy of uranium and 10 wt\% molybdenum (U-10Mo) LEU fuel with a uranium density of $15.3 \mathrm{~g} / \mathrm{cm}^{3}$. Core design using an unfinned LEU U-10Mo fuel element with 19 plates has shown acceptable performance at $7 \mathrm{MW}$, adequate safety margin to onset of nucleate boiling at a corresponding Limiting Safety System Setting (LSSS) power of $8.4 \mathrm{MW}$, and has demonstrated sufficient safety margin during transients and hypothetical accident scenarios to assure that no unacceptable consequences are possible and that regulatory requirements are met. $^{3-6}$

\subsection{Alternative General Atomics LEU Uranium-Zirconium-Hydride Fuel-Rod Core}

As an alternative to the use of U10Mo LEU fuel for MITR conversion, General Atomics (GA) has investigated the feasibility of using LEU Uranium-Zirconium-Hydride (UZrH) fuel rods with modified TRIGA $^{\circledR}$ fuel. $^{7,8}$ Using fuel rods instead of fuel plates would require significant re-design of the fuel elements. After several years of engineering design and iteration shorter, smaller diameter, rods were proposed with $45 \mathrm{wt} \%$ uranium and $19.7 \%{ }^{235} \mathrm{U}$ enrichment and a reconfigured fission gas plenum. Although the U.S. Nuclear Regulatory Commission (NRC) Safety Evaluation Report NUREG-1282 found the 20 and $30 \mathrm{wt} \%$ UZrH fuel acceptable, the $45 \mathrm{wt} \%$ fuel would require a further safety evaluation to determine acceptability. ${ }^{9}$ Massachusetts Institute of Technology (MIT) and Argonne National Laboratory (ANL) have performed their own assessment of the GA design to determine whether this design would meet the detailed conversion requirements described below including safety requirements to protect 
against critical heat flux (CHF). For this assessment, MIT expanded the capabilities of MCODE-FM, which is currently used for fuel management of the MITR HEU core, to support the fuel cycle analysis of the GA LEU UZrH fuel clusters. ${ }^{10}$ Also, MIT and ANL provided technical verifications of the GA calculations in terms of neutronic and thermal-hydraulic analyses.

As shown in Figure 2, $16 \mathrm{UZrH}$ fuel rods are used to replace the fuel plates of a rhomboid MITR fuel element. ${ }^{7}$ The LEU beginning-of-life (BOL) core has 22 rhomboid elements with a total of 352 (i.e. $22 \times$ 16) UZrH fuel rods. The equilibrium core has 24 elements with a total of 384 (i.e. $24 \times 16$ ) fuel rods. Table 1 provides key nominal fuel rod and fuel element dimensions. The cladding material is Incoloy 800. The elements employ egg-crate style grid spacers to help maintain a proper spacing between adjacent fuel rod and between fuel rods and the rhomboid can that contains the 16 fuel rods of the element.

\section{CONVERSION REQUIREMENTS}

There are five requirements for a successful conversion of MITR to LEU fuel. The first requirement is to retain the current core housing and other structures inside the reactor vessel. The fuel element size and shape must be retained. In-core changes are limited to changes within the fuel elements and replacement of the control blades if necessary.

The second requirement is to maintain the current irradiation testing capabilities. This means that the neutron flux levels in the beam tubes and in-core irradiation facilities must be maintained. MCNP calculations, which were performed with the aid of the MCNP code ${ }^{11}$, indicate that a reactor power level of about $8.5 \mathrm{MW}$ is required for the UZrH fuel design to maintain the current HEU core irradiation testing capabilities. If the nominal power is $8.5 \mathrm{MW}$, then the LSSS power would be about 10-20\% higher, or about $9.4-10 \mathrm{MW}$.

The third requirement is that the maximum core flow rate is limited to a value of $0.151 \mathrm{~m}^{3} / \mathrm{s}$ ( $2400 \mathrm{gpm})$. This limitation is required to avoid the possibility of vibration from fluid-structure interactions in the primary coolant pipe located in the biological shield where it would be difficult to repair or to replace. A core flow rate of $0.151 \mathrm{~m}^{3} / \mathrm{s}$ corresponds to a coolant velocity of approximately 6 $\mathrm{m} / \mathrm{s}$, or $20 \mathrm{ft} / \mathrm{s}$, in the critical pipe. Vibration is not expected at or below this velocity. Therefore, it was decided to set the maximum allowed core flow rate at $0.151 \mathrm{~m}^{3} / \mathrm{s}$ and the LSSS value at $0.139 \mathrm{~m}^{3} / \mathrm{s}$ (2200 gpm).

The fourth requirement is that the minimum shut-down margin be maintained at all times in the fuel cycle. Also, the fuel should obtain reasonable fuel burn-up and fuel cycle length. The current HEU core has a cycle length of 40-50 days. Fuel cycle calculations indicate that the UZrH-fueled core could meet the minimum shut-down margin requirement at all times in the burn-up cycle, although this may require replacing the current control blades with higher-worth blades.

The fifth requirement is that the appropriate safety requirements, including a minimum margin to CHF, be satisfied. NUREG-1537, Part $1^{12}$ on Page 5 of Appendix 14.1, "Format and Content of Technical Specifications for Non-Power Reactors", of Chapter 14, "Technical Specifications," states:

Safety limits should preclude flow instabilities in the hottest channel and ensure that the minimum departure from nucleate boiling ratio (DNBR) is at least 2.0 (which has been an acceptable margin to the onset of nucleate boiling). This analysis should range over all physical and engineering parameters of the fuel components, the core 


\section{configurations, and the coolant systems, and should also include consideration for}

uncertainties.

This statement is in the subparagraph for reactors with engineered cooling systems (2.1.2), which on page 4 of Appendix 14.1 in subparagraph 2.1.1 is defined as a reactor with a forced-convection cooling. MITR has a forced-convection primary cooling system. As found in literature studying departure from nucleate boiling (DNB), DNB and CHF are used interchangeably in this paper. ${ }^{13}$

For the current HEU plate fuel core, and for the proposed LEU plate fuel core, the main steadystate safety requirement is to avoid OFI. For these cores OFI is more limiting than CHF. In order to provide additional safety margin, the safety criterion adopted for the plate fuel cores is to avoid onset of nucleate boiling (ONB) since CHF and OFI occur after ONB.

For the proposed UZrH fuel-rod core the margin to CHF is studied. The margin to OFI has not been studied, but may need to be considered if the margin to $\mathrm{CHF}$ is acceptable.

\section{ANALYTICAL MODELING}

\subsection{Thermal-Hydraulics System Model of the MITR Fuel-Rod Core}

The thermal-hydraulics system model of the MITR fuel-rod core was developed by Bolin of General Atomics. ${ }^{7}$ The model was implemented with the RELAP5/MOD3.3 computer code. ${ }^{14}$ In the analytical modeling the flow area inside the element with the highest power fuel rod is divided into subchannels of the four geometries - interior channel, side channel, $60^{\circ}$ corner channel, and $120^{\circ}$ corner channel - as indicated in Figure 2. The figure shows two subchannels of each of these types. The interior subchannel next to the rod at the bottom corner rod in the figure has the highest rod power among all of the rods that are next to interior channels. Therefore, in the model this subchannel is a separate flow path. All of the other interior subchannels in the element are grouped together into a single subchannel, which has the total flow area and total power of all of these other interior subchannels. In the model the hydraulic diameter of both interior channels in the model is the same. The other three types of subchannels are treated in an analogous manner. Thus, the entire element is modeled by eight parallel heated channels. Since the hottest rod in the core is adjacent to a $60^{\circ} \mathrm{corner}$ subchannel, the hottest interior and side subchannels are also modeled adjacent to this rod. The fourth hot subchannel type, a $120^{\circ}$ corner, with the hottest rod in the core adjacent to a $120^{\circ}$ corner was present in the same element and was also modeled. Thus, the model accounts for the hottest rod in the core for each of the four channel types.

In the modeling of the element with the hottest rod, the heat from each rod is assumed to dissipate only in the radial direction relative to the center of the rod, i.e., there is no azimuthal and no axial heat transfer within the rod. The eight subchannels models form eight parallel paths in a flow network that has a common plenum at the inlet and another common plenum at the outlet. In the model there is no heat transfer or coolant exchange among the eight parallel subchannel paths. Table 2 provides key model parameters of the four individual subchannel types, including the hydraulic and heated diameters. By definition, the hydraulic diameter is four times the flow area divided by the wetted perimeter and the heated diameter is four times the flow area divided by the heated perimeter. 
In the RELAP5/MOD3.3 model, all of the other elements except for the one with the highest power rod are grouped together into four parallel paths. Each of these four paths represents a group of elements.

In addition to the 12 heated parallel flow paths - eight for the element with the hottest rod and four to represent the remaining elements - there are two unheated parallel path to represents bypass flows and flow through the unfueled rhomboid element locations in the core.

\subsection{Critical Heat Flux Model}

The critical heat flux model used in the analysis employs the 2006 CHF look-up table provided by Groeneveld, et al. ${ }^{15}$ This is three-dimensional table, $\mathrm{CHF}_{\text {table }}(P, G, X)$, that provides discreet $\mathrm{CHF}$ values as a function of discreet values of exit pressure $(P)$ between 1 and 210 bar, mass flux $(G)$ between 0 and $8000 \mathrm{~kg} / \mathrm{m}^{2}-\mathrm{s}$, and exit equilibrium quality $(X)$ between -0.5 and 1.0. Linear interpolation is used to find CHF values for values of $P, G$, and $X$ within the range of the table.

The CHF values from the Groeneveld look-up table are for flow inside a circular uniformly heated $8 \mathrm{~mm}$ diameter tube that is heated from the outside. For other conditions the look-up table value is multiplied by a set of factors. In the current analysis, four factors are used, yielding the following relationship for $\operatorname{CHF}(P, G, X)$ :

$$
\operatorname{CHF}(P, G, X)=\operatorname{CHF}_{\text {table }}(P, G, X) K_{1} K_{2} K_{3} K_{4}
$$

where

$\mathrm{K}_{1}$ is a factor to account for deviations from the $8 \mathrm{~mm}$ hydraulic and heated diameter.

$\mathrm{K}_{2}$ is a factor to account for deviation from a circular tube to a rod bundle.

$\mathrm{K}_{3}$ is a factor to account for the effect of rod grid spacers.

$\mathrm{K}_{4}$ is a factor to account for heated length.

Groeneveld also uses a factor $\mathrm{K}_{5}$ to account for axially non-uniform heat flux. For quality $(\mathrm{X})$ less than zero, $K_{5}=1.0$. In all cases in this analysis the quality is less than zero, even at $C H F$, so $K_{5}$ is not included explicitly in Eq. (1).

\subsection{1. $K_{1}$ CHF Factor (Diameter)}

Groeneveld, et al. ${ }^{15}$ recommend:

$$
K_{1}=(8 / D)^{n}
$$

where $D$ is the diameter in millimeters and $n$ is $1 / 2$. No distinction is made between heated and hydraulic diameter. However, in another paper in which Groeneveld is an author, $\mathrm{D}$ is heated diameter and $\mathrm{n}$ is $1 / 3 .{ }^{16}$ Kalimullah, et al. ${ }^{17}$ researched the work of Groeneveld and others ${ }^{178-20}$ and recommended that D be heated diameter and $\mathrm{n}$ be 0.312 for sub-cooled boiling. If sub-cooled boiling is not involved, then $\mathrm{n}=$ 0.5. These recommendations are used in the current work. Also, for $D>25 \mathrm{~mm}, \mathrm{D}=25 \mathrm{~mm}$ is used.

\subsection{2. $\mathrm{K}_{2}$ CHF Factor (Rod Bundle)}

At least two sources provide relationships for $K_{2}$. Equation (3) is from Groeneveld, et al. ${ }^{21}$ 
where

$$
K_{2}=\min \left\{1,(1 / 2+2 \delta / d) \exp \left(-x^{1 / 3} / 2\right)\right\}
$$

$$
\begin{aligned}
& \delta=\text { gap size } \\
& d=\text { rod diameter }
\end{aligned}
$$

Equation (4) is from Groeneveld, et al. ${ }^{16}$

$$
K_{2}=\min \left[0.8,0.8 \exp \left(-0.5 X^{1 / 3}\right)\right]
$$

When Eq. (3) or Eq. (4) is evaluated for the cases of interest in this paper, $\mathrm{K}_{2}$ came out to about 0.8 . Therefore, $\mathrm{K}_{2}=0.8$ was used for the work reported in this paper.

\subsection{3. $\quad K_{3}$ CHF Factor (Grid Spacers)}

Obtaining an accurate value for the grid spacer effect in the MITR with UZrH fuel rods is a special problem because grid spacer geometry is complex, the effect is a function of more than one or two simple variables, most of the existing measured data for grid spacer effects on $\mathrm{CHF}$ is considered proprietary and is not in the open literature, and the data that is in the open literature was measured for conditions quite different from those in MITR. Tong and Tang ${ }^{22}$ on pages 404 and 405 states:

Most reactor vendors test flow boiling crisis on their typical rod bundle geometries with their proprietary spacer grid design and operate the test section in the same ranges as the reactor operates. From their own test data, each of the vendors then separately develops their CHF correlation in their proprietary subchannel code for application in their product design. While research laboratories and universities have tested the boiling crisis in a wide range of operating conditions and have developed more generalized CHF correlations, they aim at understanding the nature of the trend of boiling crisis.

Also, Groeneveld et al. ${ }^{23}$ on page 1 report that grid spacers usually have a significant beneficial effect on $\mathrm{CHF}$, but some researchers also report that flow obstacles can sometimes have a detrimental effect on $\mathrm{CHF}$. The notion that although grid spacers can enhance $\mathrm{CHF}$, sometimes they have a detrimental effect is also stated in item 5 on page 215 of Groeneveld, et al. ${ }^{24}$. Here they report up to $20 \%$ reduction in CHF in a 16-rod bundle due to it having egg crate-type spacers.

The equations used for $\mathrm{K}_{3}$ by Groeneveld, et al. ${ }^{21}$, Groeneveld, et al. ${ }^{16}$, and Groeneveld, et al. ${ }^{23}$ are:

$$
\begin{gathered}
K_{3}=1+A \exp \left[-B L_{s p} / D_{\text {hy }}\right] \\
A=1.5 K^{0.5}(0.001 G)^{0.2} \\
B=0.1
\end{gathered}
$$

where 
$\mathrm{K}$ is pressure loss (or form loss) coefficient

$D_{\text {hy }}$ is the hydraulic diameter

$L_{s p}$ is the spacing between grid spacers

$\mathrm{G}$ is the mass flux in $\mathrm{kg} / \mathrm{m}^{2}$-s.

In Groeneveld, et al. ${ }^{21} \mathrm{~L}_{\text {sp }}$ is not defined. In Groeneveld, et al. ${ }^{16} \mathrm{~L}_{\text {sp }}$ is the distance from the upstream spacer plane. In Groeneveld, et al. ${ }^{23} \mathrm{~L}_{\mathrm{sp}}$ is defined as either the spacer pitch or the distance from the obstacle upstream. In Groeneveld, et al. ${ }^{24} L_{\text {sp }}$ is defined as the spacer pitch. In the current work $L_{s p}$ is taken to be the spacer pitch. Table 1 of Groeneveld, et al. ${ }^{23}$ indicates that the expressions for $A$ and $B$ in Eq. (6) and (7) are approximate values and were derived based on pressurized heavy water reactors. Nothing is said about applicability to other types of reactors. In the RELAP5 analysis, the pressure loss coefficient, $K$, was taken to be 0.37 . Table 3 provides estimates of the values of $G$ and $K_{3}$ for each of the four hot channel types in the hot element. The channel velocity in $\mathrm{m} / \mathrm{s}$ can be obtained by dividing $\mathrm{G}$ by 1000 because the density was estimated to be $1000 \mathrm{~kg} / \mathrm{m}^{3}$ for the evaluation of $\mathrm{K}_{3}$. There are three grid spacers in fuel rod each element. The distance between the first and second grid spacer is $25.40 \mathrm{~cm}$. The distance between the second and third grid spacer is $15.88 \mathrm{~cm}$. Thus, there is a $K_{3}$ value for each of these two values of $L_{s p}$ for each of the four limiting subchannel types in the element with the hottest rod. Although Eq. (5) produces values up to about 1.1, $\mathrm{K}_{3}$ would be between 1.00 and 1.01 in the channels which are most limiting with respect to $\mathrm{CHF}$, the $120^{\circ}$ corner channel. Although, as indicated earlier, $K_{3}$ could be less than 1.0, in this work $K_{3}$ is set to 1.0 .

\subsection{4. $\mathrm{K}_{4}$ CHF Factor (Heated Length)}

The following equation is provided in Groeneveld, et al. ${ }^{21}$ :

$$
K_{4}=\exp \left[\left(D_{h y} / L\right) \exp \left(2 \alpha_{h}\right)\right] \quad \text { if } L / D_{h y}>5
$$

where

$L$ is heated length

$\alpha_{h}$ is vapor fraction $=X \rho_{f} /\left[X \rho_{f}+(1-X) \rho_{g}\right]$

$\rho_{\mathrm{f}}$ is liquid density at saturation

$\rho_{\mathrm{g}}$ is vapor density at saturation

\subsection{Implementation of Critical Heat Flux Model}

RELAP5/MOD3.3 does not contain the above Groeneveld 2006 CHF treatment; it contains an earlier Groeneveld CHF treatment. The Groeneveld 2006 CHF tables are based on significantly more experimental data than earlier Groeneveld versions. Therefore an external calculation outside of the RELAP5/MOD3.3 code was used to obtain the CHF values. For each axial node in each of the hotter channels the coolant, pressure, mass flux, vapor quality, and fuel rod surface heat flux were obtained from the RELAP5 output, with modifications to the RELAP5 values to account for engineering hot channel factors where appropriate, and then used in an external calculation to determine the $\mathrm{CHF}$ ratios.

The following computational procedure was used: 
1. RELAP5 cases were run for the Beginning-of-Life $(B O L)$ core and equilibrium core (which are described in Section 3.4). Both were assumed to be at 8.5 MW and did not include engineering hot channel factors. These are the only RELAP5 runs used in this work. As explained in No. 3, below, results for other reactor power levels were obtained by scaling the outputs from these two cases. As explained in No. 4, below, hot channel factors were included by analogous scaling.

2. The RELAP5 output for the limiting channels was used to obtain pressure, mass flux, coolant quality, and clad surface heat flux at each axial node to obtain the CHF ratio at each axial level.

3. For nominal results at higher power levels the RELAP5 $8.5 \mathrm{MW}$ results were modified by increasing the heat flux and the enthalpy rise from the inlet by the ratio of the higher power to $8.5 \mathrm{MW}$. For cases with hot channel factors, a heat flux multiplier of 1.121 was used and a bulk enthalpy rise factor of 1.201 was used to scale the nominal results. These multipliers are based on uncertainties in measured and computed power levels and coolant flow rates.

4. The coolant qualities were re-calculated based on the modified values of enthalpy.

5. The axial nodes were scanned to find the minimum value of $\mathrm{CHF}$ ratio.

\subsection{Rod Powers and Axial Power Shapes}

MITR LEU UZrH cores were analyzed with MCNP in order to obtain power distributions. Core configurations analyzed were a Beginning-of-Life (BOL) core, which is all fresh fuel, and an equilibrium core that represents elements loaded with a variety of different burnup levels that would allow continuous fuel management. Due to shutdown margin requirements, only 22 fuel elements are loaded into the BOL core, whereas in the equilibrium core 24 fuel elements are loaded. Since 27 positions are available for loading fuel elements in the MITR reactor, the remaining positions can be used for in-core experimental irradiation vehicles. Neutronic power distributions were analyzed at beginning-of-cycle, xenon equilibrium, and at the end of the cycle. The beginning-of-cycle power distributions yielded the highest rod power factors for both the BOL and equilibrium cores, and so these were used for the RELAP5 analysis. The power distributions generated are presented in Table 4. This table shows higher peak heat flux in the equilibrium core than the BOL core. Also, the equilibrium cores will have a lower flow per element since flow is distributed among more elements. In this case, both power and flow would be expected to cause the equilibrium core to be more limiting. Nevertheless both the BOL and equilibrium cores are typically analyzed.

\section{RESULTS}

Table 5 lists minimum values of CHF ratio (CHFR) for each of the hot channels in the element with the hottest fuel rod. In the table the minimum CHFR of each column is shown in bold. The nominal case at $\mathrm{BOL}$ and $8.5 \mathrm{MW}$ has a minimum CHFR of 2.30 in analysis where hot channel factors were not included. Due to the regulatory requirement for reactors with engineered cooling systems (i.e., with forced-convection cooling pumps), as quoted in Section 2, the CHF ratio analysis should include consideration for uncertainties. Therefore, the analysis has incorporated hot channel factors to account for uncertainties regarding measurement and calculation of flow, power, and channel dimensions. For this reason the comparison to the regulatory requirements for minimum CHFR (DNBR) of 2.0 in should be to the results that include hot channel factors. The remaining four cases in Table 5 assume LSSS power and also include engineering hot channel factors. Two core states, BOL and equilibrium were evaluated since it was not evident which would be more limiting. CHFR was lower in the equilibrium cores than $\mathrm{BOL}$ in all cases. Since MITR operations require regular refuelings during each year, and this requirement would continue with LEU fuel, the equilibrium core must meet the CHFR requirement. The $\mathrm{BOL}$ core results would only be applicable for a short time prior to any substantial operation. 
It is notable that all equilibrium cores evaluated with hot channel factors have minimum CHF ratios considerably less than 2.0. Recall that the regulatory requirement states safety limits should ensure the minimum CHFR is 2.0. Therefore, to meet the CHFR requirement, the LSSS power the reactor would operate with should be considered instead of the nominal power. For a nominal power of 8.5 MW, a 10 MW LSSS power would provide a margin to scram setpoint and LSSS power that is consistent with the margin MITR currently uses for operation. For the equilibrium core with hot channel factors included and evaluated consistent with an LSSS of $10 \mathrm{MW}$, the minimum CHFR is 1.41.

If LSSS power were reduced to approximately $10 \%$ over the nominal power instead of the desired $20 \%$, then the LSSS power would be $9.4 \mathrm{MW}$, and the minimum CHFR would be 1.51 . Even in this case where operations may be impeded, the CHFR remains substantially below ( $25 \%$ below). The $\mathrm{NRC}$ requirement that the minimum CHFR be at least 2.0 over the full range of parameters and including consideration for uncertainties.

It is noteworthy that these results were calculated, as described above, externally to RELAP5 based on nominal power without hot channel factors. Ideally this analysis would have been done directly in RELAP5 at power levels associated with LSSS and with hot channel factors. This was attempted. However, significant difficulties were encountered due to challenging flow conditions. We believe that these difficulties are the result of the prediction of appreciable voids. In contrast, the external methodology allowed calculation of CHFR since it did not consider the generation of local voids as steam bubbles. Such voids would retard the flow in the hot channel and reduce the critical heat flux. Analysis directly using RELAP5, which includes voids, would yield the same or lower value of CHFR if computations were successful. Thus calculation directly with RELAP5 would be more conservative in some cases. Applying factors external to RELAP5 is acceptable here since CHFR remained below the required 2.0.

\section{CONCLUSIONS}

Five requirements for a successful conversion of MITR to LEU fuel have been discussed. Operating a UZrH fueled MITR core with an LSSS power of $10 \mathrm{MW}$ would allow all of the conversion requirements to be met except for the safety requirements. Based on the present analysis, in order to meet the minimum CHF ratio requirement at LSSS power, and with engineering hot channel factors included, the nominal reactor core power would need to be reduced substantially, by at least $25 \%$. This reduction would downgrade the irradiation performance of the reactor to an unacceptable level.

Several iterations of the design have been undertaken during the course of this conversion work, and significant further improvement to the rod design or fuel management would not be trivial. In particular, the rod design is of a smaller diameter and higher uranium weight fraction than is currently licensed in the United States. This 45 wt\% uranium fuel of smaller diameter has, however, been operated internationally in a reactor with the standard fuel rod length and fission gas plenum. For this reason, if a variant rod design were optimized to something that has not been fabricated or irradiated previously, then the scale of the undertaking would be increased significantly. Alternatively, developing other safety analysis methods for licensing, or conducting experimental programs, to improve the analyzed safety margin would need to be undertaken. Evaluation of these mitigations is beyond the scope of this work. 


\section{ACKNOWLEDGEMENTS}

The authors express their gratitude to Chris Ellis, John Bolin, and Anthony Veca of General Atomics for their efforts which lead to this fuel design evaluation, and to Tom Newton for sharing his expertise regarding MITR. This work was sponsored by the U.S. Department of Energy, Office of Material Management and Minimization, National Nuclear Security Administration Defense Nuclear Nonproliferation Office under Contract DE-AC02-06CH11357. 


\section{REFERENCES}

1. MITR-Staff, Safety Analysis Report for the MIT Research Reactor, MIT-NRL-11-01, MIT Nuclear Reactor Laboratory (2011).

2. T.H. Newton, Jr., Development of a Low Enrichment Uranium Core for the MIT Reactor, PhD Thesis, Massachusetts Institute of Technology (2006).

3. A. Bergeron, E.H. Wilson, G. Yesilyurt, F.E. Dunn, J.G. Stevens, L. Hu, and T. H. Newton, "Low Enriched Uranium Core Design for the Massachusetts Institute of Technology Reactor (MITR) with Un-finned 12 mil-thick Clad UMo Monolithic Fuel", ANL/GTRI/TM-13/15, Argonne National Laboratory (November 2013).

4. F.E. Dunn, A.P. Olson, E.H. Wilson, K. Sun, T.H. Newton, Jr., and L.-W. Hu, "Preliminary Accident Analysis for Conversion of the Massachusetts Institute of Technology Reactor (MITR) from Highly Enriched to Low Enriched Uranium," ANL/GTRI/TM-13/5, Argonne National Laboratory (July 2013).

5. L.-W. Hu, et al., "Accident Analyses for the MIT Research Reactor (MITR) Conversion from Highly Enriched Uranium to Low Enriched Uranium Using an Unfinned Fuel Element," RERTR-2015: $36^{\text {th }}$ International Meeting on Reduced Enrichment for Research and Test Reactors, Seoul, Korea (October 11-14, 2015).

6. K. Sun, L-W Hu, T. H. Newton, Jr., S. M. Don, E. H. Wilson, F. Dunn, J. Stillman, A. Bergeron, and A. Olson, "Updates on Conversion of the MIT Research Reactor (MITR) from Highly Enriched Uranium to Low Enriched Uranium including Accident Analysis," European Research Reactor Conference 2016, Berlin, Germany (March 13-17, 2016).

7. J. Bolin, "Thermal Hydraulic Results of a Feasibility Study of LEU UZrH Fuel for the MITR," slide presentation, 2015 Conference of the Test, Research, and Training Reactors (TRTR), Brewster, Massachusetts (October 4-9, 2015).

8. C. Ellis, "Neutronic Results of a Feasibility Study of LEU UZrH Fuel for the MITR," slide presentation, 2015 Conference of the Test, Research, and Training Reactors (TRTR), Brewster, Massachusetts (October 4-9, 2015).

9. Safety Evaluation Report on High-Uranium Content, Low-Enriched Uranium-Zirconium Hydride Fuels for TRIGA Reactors, NUREG-1282, U.S. Nuclear Regulatory Commission (August 1987).

10. K. Sun, et al., Expanding Fuel Management Capabilities of MCODE-FM in Support of the MIT Research Reactor (MITR-II) LEU Conversion Using UZrH Fuel, MIT-NRL-14-03, Rev. 1, MIT Nuclear Reactor Laboratory (February 2014).

11. X-5 Monte Carlo Team, MCNP-A General Monte Carlo N-Particle Transport Code, Version 5 Volume I, II and III, LA-UR-03-1987/LA-CP-03-0245/LA-CP-03-0284, Los Alamos National Laboratory (2003).

12. Guidelines for Preparing and Reviewing Applications for the Licensing of Non-Power Reactors, Format and Content, NUREG-1537, Part 1, U.S. Nuclear Regulatory Commission (February 1996). 
13. M. M. El-Wakil, Nuclear Heat Transport, American Nuclear Society, La Grange Park, IL, p. 303 (1993).

14. RELAP5/MOD3.3 CODE MANUAL, distributed by Nuclear Safety Analysis Division, Information Systems Laboratories, Inc., Rockville, Maryland and Idaho Falls, Idaho (March 2003).

15. D.C. Groeneveld, J.Q. Shan, A.Z. Vasić, L.K.H. Leung, A. Durmayaz, J. Yang, S.C. Cheng, and A. Tanase, “The 2006 CHF look-up table," Nuclear Engineering and Design 237 (2007) 1909-1922.

16. D.C. Groeneveld, S. C. Cheng and T. Doan, "1986 AECL-UO Critical Heat Flux Lookup Table," Heat Transfer Engineering 7 (1986) $46-62$.

17. M. Kalimullah, E.E. Feldman, A.P. Olson, B. Dionne, J.G. Stevens, and J.E. Matos, "An Evaluation of Subcooled CHF Correlations and Databases for Research Reactors Operating at 1 to 50 bar Pressure", RERTR-2012: $33^{\text {rd }}$ International Meeting on Reduced Enrichment for Research and Test Reactors, Warsaw, Poland (October 14-17, 2012).

18. A. Tanase, S.C.Cheng, D.C. Groeneveld, and J.Q. Shan, "Diameter Effect on Critical Heat Flux," Nucl. Eng. Des. 239 (2009) 289-294.

19. G.P. Celata, M. Cumo, and A. Mariani, "The Effect of the Tube Diameter on the Critical Heat Flux in Subcooled Flow Boiling," Inter. J. of Heat and Mass Transfer, 39 (1966) 1755-1757.

20. D.D. Hall and I. Mudawar, "Ultra-high Critical Heat Flux (CHF) for Subcooled Flow Boiling - II. CHF Database and Design Equations," Inter. J. of Heat and Mass Transfer, 42 (1999) 11429-1456.

21. D.C. Groeneveld, L.K.H. Leung, Y. Guo, A. Vasic, M. El Nakla, S.W. Peng, J. Yang, and S.C. Cheng, "Lookup Tables for Predicting CHF and Film-Boiling Heat Transfer: Past, Present, and Future," Nuclear Technology 152 (2005) 87-104.

22. L.S. Tong and Y.S. Tang, Boiling Heat Transfer and Two-Phase Flow, Second Edition, Taylor \& Francis, Washington, D. C. (1997).

23. D.C. Groeneveld, I.L. Pioro, Y.Guo, S.C. Cheng, Yu. V. Antoshko, S.S. Doerffer, A.Z. Vasic, "A Study of the Effect of Flow Obstacles on the Critical Heat Flux," AECL-12104, FFC-FCT-333, AECL Chalk River Laboratories, Chalk River, Ontario Canada (2001).

24. D. C. Groeneveld and C. W. Snoek, "A Comprehensive Examination of Heat Transfer Correlations Suitable for Reactor Safety Analysis," Chapter 3, pp. 181-274, G. F. Hewitt, J. M. Delhaye, and N. Zuber, (editors), Multiphase Science and Technology, Volume 2, Hemisphere Publishing Corporation, Washington (1986). 


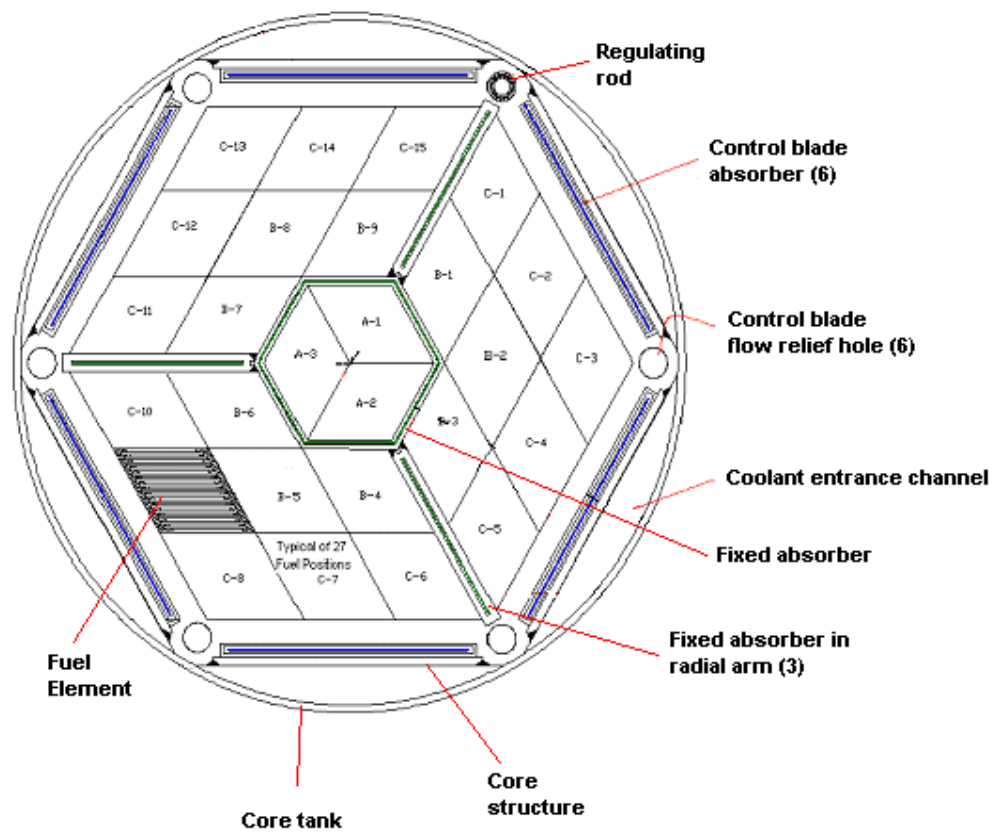

Figure 1. Layout of the MIT Reactor core

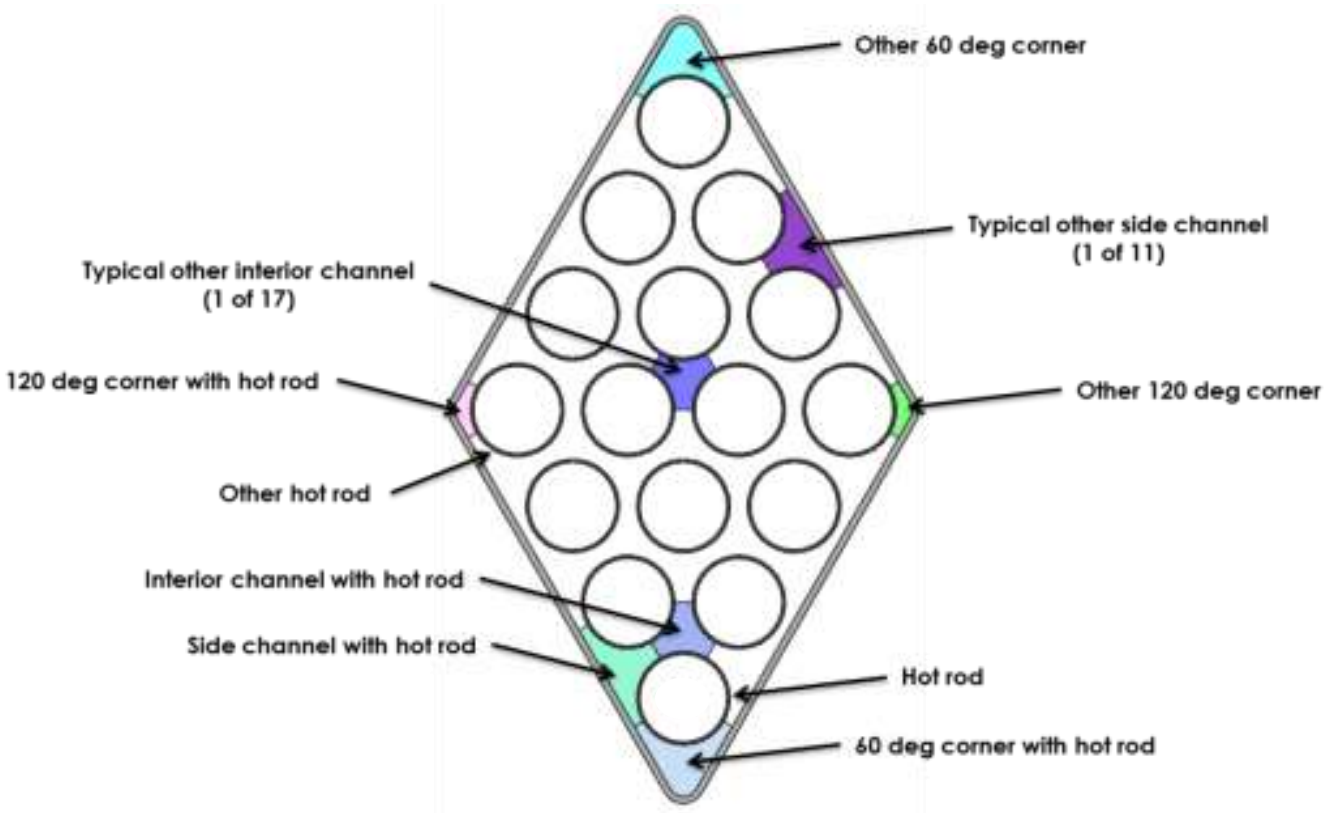

Figure 2. MITR Fuel Element with LEU UZrH rod type Fuel, Flow Channel Model ${ }^{7}$ 
Table 1

Element Fuel Rod Geometry.

\begin{tabular}{|l|l|}
\hline Rods Per Element & 16 \\
\hline Rod Outer Diameter & $13.77 \mathrm{~mm}$ \\
\hline Rod pitch & $16.312 \mathrm{~mm}$ \\
\hline Gap between Rods & $2.542 \mathrm{~mm}$ \\
\hline Active Fuel length & $0.508 \mathrm{~m}$ \\
\hline Fuel Outer Diameter & $12.93 \mathrm{~mm}$ \\
\hline Clad wall thickness & $0.410 \mathrm{~mm}$ \\
\hline
\end{tabular}


Table 2

Thermal-Hydraulics Model Parameters for Individual Subchannel Types.

\begin{tabular}{|l|c|c|c|c|c|}
\hline $\begin{array}{c}\text { Subchannel } \\
\text { Type }\end{array}$ & $\begin{array}{c}\text { Hydraulic } \\
\text { Diameter, } \mathrm{mm}\end{array}$ & $\begin{array}{c}\text { Heated } \\
\text { Diameter, } \mathrm{mm}\end{array}$ & $\begin{array}{c}\text { Flow Area, } \\
\mathrm{mm}^{2}\end{array}$ & $\begin{array}{c}\text { Rods per } \\
\text { Subchannel }\end{array}$ & $\begin{array}{c}\text { Flow Area per } \\
\text { Rod, } \mathrm{mm}^{2}\end{array}$ \\
\hline Side & 6.4447 & 11.31 & 61.16 & $1 / 2$ & 122.32 \\
\hline $60^{\circ}$ Corner & 6.4668 & 38.74 & 69.82 & $1 / 3$ & 209.46 \\
\hline Interior & 7.584 & 7.584 & 41.01 & $1 / 2$ & 82.02 \\
\hline $120^{\circ}$ Corner & 3.5718 & 8.3226 & 15.00 & $1 / 6$ & 90.00 \\
\hline
\end{tabular}


Table 3

Evaluation of the $\mathrm{K}_{3}$ Grid Spacer Factor for Various Subchannels.

\begin{tabular}{|c|c|c|c|c|}
\hline $\begin{array}{c}\text { Subchannel } \\
\text { Type }\end{array}$ & $\begin{array}{c}\mathrm{G} \\
\mathrm{kg} / \mathrm{m}^{2}-\mathrm{s}\end{array}$ & $\begin{array}{c}\text { Hydraulic } \\
\text { Diameter, } \\
\mathrm{mm}\end{array}$ & $\begin{array}{c}\mathrm{L}_{\mathrm{sp}}, \mathrm{cm} \\
\text { Lower \& } \\
\text { Upper }\end{array}$ & $\begin{array}{c}\mathrm{K}_{3} \\
\text { Lower \& } \\
\text { Upper }\end{array}$ \\
\hline Side & 3160 & 6.4447 & $\begin{array}{l}25.40 \\
15.88\end{array}$ & $\begin{array}{l}1.0223 \\
1.0978\end{array}$ \\
\hline $\begin{array}{l}60^{\circ} \\
\text { Corner }\end{array}$ & 3060 & 6.4668 & $\begin{array}{l}25.40 \\
15.88\end{array}$ & $\begin{array}{l}1.0225 \\
1.0979\end{array}$ \\
\hline Interior & 3480 & 7.584 & $\begin{array}{l}25.40 \\
15.88\end{array}$ & $\begin{array}{l}1.0405 \\
1.1428\end{array}$ \\
\hline $\begin{array}{l}120^{\circ} \\
\text { Corner }\end{array}$ & 2460 & 3.5718 & $\begin{array}{l}25.40 \\
15.88\end{array}$ & $\begin{array}{l}1.0009 \\
1.0128\end{array}$ \\
\hline
\end{tabular}


Table 4

Axial Power Distribution in Fuel Rods Adjacent to Various Hot Subchannels.

\begin{tabular}{|c|c|c|c|c|}
\hline \multirow[b]{2}{*}{$\begin{array}{l}\text { Distance from } \\
\text { the Bottom of } \\
\text { the Fuel }(\mathrm{cm})\end{array}$} & \multicolumn{4}{|c|}{ Hot Rod Heat Flux $\left(\mathrm{W} / \mathrm{cm}^{2}\right)$} \\
\hline & $\begin{array}{l}60^{\circ} \text { Corner, } \\
\text { Side, and } \\
\text { Interior } \\
\text { - BOL Core }\end{array}$ & $\begin{array}{l}120^{\circ} \text { Corner } \\
\text { - BOL Core }\end{array}$ & $\begin{array}{c}60^{\circ} \text { Corner, Side, } \\
\text { and Interior } \\
\text { - Equilibrium } \\
\text { Core }\end{array}$ & $\begin{array}{c}120^{\circ} \text { Corner } \\
\text { - Equilibrium } \\
\text { Core }\end{array}$ \\
\hline 1.59 & 170.7 & 176.6 & 148.8 & 156.6 \\
\hline 4.76 & 185.1 & 175.7 & 169.3 & 175.4 \\
\hline 7.94 & 202.0 & 192.8 & 197.6 & 185.5 \\
\hline 11.11 & 221.6 & 201.9 & 212.8 & 209.9 \\
\hline 14.29 & 232.6 & 209.9 & 227.9 & 211.0 \\
\hline 17.46 & 243.5 & 215.5 & 238.5 & 216.8 \\
\hline 20.64 & 246.7 & 219.8 & 255.9 & 228.9 \\
\hline 23.81 & 244.9 & 216.1 & 255.2 & 232.1 \\
\hline 26.99 & 237.6 & 212.8 & 249.1 & 220.3 \\
\hline 30.16 & 232.3 & 206.2 & 241.5 & 227.5 \\
\hline 33.34 & 230.7 & 198.1 & 228.9 & 220.2 \\
\hline 36.51 & 209.8 & 182.5 & 208.0 & 197.5 \\
\hline 39.69 & 187.2 & 159.5 & 187.2 & 172.7 \\
\hline 42.86 & 159.6 & 137.9 & 159.7 & 148.1 \\
\hline 46.04 & 136.3 & 121.4 & 132.2 & 127.7 \\
\hline 49.21 & 119.0 & 107.6 & 117.5 & 111.4 \\
\hline
\end{tabular}


Table 5

Minimum CHF Ratio for Channel with Hot Rod.

\begin{tabular}{|l|c|c|c|c|c|}
\hline Reactor Power & $8.5 \mathrm{MW}$ & $9.4 \mathrm{MW}$ & $9.4 \mathrm{MW}$ & $10.0 \mathrm{MW}$ & $10.0 \mathrm{MW}$ \\
\hline $\begin{array}{l}\text { Fuel Cycle } \\
\text { State }\end{array}$ & $\begin{array}{c}\text { Beginning } \\
\text { of Life }\end{array}$ & $\begin{array}{c}\text { Beginning } \\
\text { of Life }\end{array}$ & Equilibrium & $\begin{array}{c}\text { Beginning } \\
\text { of Life }\end{array}$ & Equilibrium \\
\hline $\begin{array}{l}\text { Hot Channel } \\
\text { Factors }\end{array}$ & $\begin{array}{c}\text { Not } \\
\text { Included }\end{array}$ & Included & Included & Included & Included \\
\hline Channel Type & & & & & \\
\hline Side & 2.49 & 1.91 & 1.74 & 1.76 & 1.60 \\
\hline $60^{\circ}$ Corner & $\mathbf{2 . 3 0}$ & $\mathbf{1 . 8 0}$ & 1.67 & 1.67 & 1.55 \\
\hline Interior & 2.67 & 1.96 & 1.81 & 1.80 & 1.65 \\
\hline $120^{\circ}$ Corner & 2.57 & 1.83 & $\mathbf{1 . 5 1}$ & $\mathbf{1 . 6 6}$ & $\mathbf{1 . 4 1}$ \\
\hline
\end{tabular}

